\title{
Geo-Prospecting Approach in The Service of The Land and Real Estate Development
}

\author{
Abdessalam HIJAB* \\ Polytechnic University of Hauts-de-France, Visual and Urban Design Laboratory (DeVisu), France
}

Submission: April 15, 2021; Published: June 01, 2021

"Corresponding author: Abdessalam HIJAB, Univ. Polytechnique Hauts-de-France, EA 2445 - DeVisu - Visual and Urban Design Laboratory, F-59313 Valenciennes, France

Abstract

In this article, we discuss an approach we called "Geo-Prospecting" based on the geo localization of urban planning and land data in vector mode. The goal is to better control and enhance the value of real estate by the developers themselves without the need for multiple intermediaries. Our proposal allows prospectors, using information and communication technologies (ICTs) moving on foot or by vehicle to access data more efficiently in real time, such as the delimitation of buildable areas, development roads, green spaces and facilities. This is possible thanks to the coupling of ICTs with geographic information system tools giving a geo localized representation of urban plans, parcel plans and their descriptive information.

Our approach allows the integration of useful data for land prospecting on a territory, which not only optimizes time and costs, but also simplifies land prospecting and develops real estate field in general. It also contributes to the implementation of democratic governance and simplified access to information. We have experimented the method on the territory of Casablanca-Settat region in Morocco, using an online and spatially referenced platform called "Geo-P- Land".

Keywords: ICTs; GIS; GPS; Geo-Prospecting; Land; Territory; Urban planning

\section{Context and Problematic}

Real estate development is one of the riskiest activities of firms [1-3]. Since the creation of real estate is in many cases speculative and therefore in anticipation of unknown future demand, risk and uncertainty are key elements of real estate development ${ }^{1}[2,4-8]$. Gehner [9] argues that "real estate development is conscious risktaking". Indeed, in the real estate field, it has been shown that the search for land to subdivide or build on is not easy: it requires the use of many skills to be effective. Land prospecting requires the mastery and availability of several geographic and alphanumeric multi-source and multi-scale data related to urban planning, the environment, land registry, etc. In real estate, there are several constraints, particularly related to the complexity and availability of information that makes land development slow. Our objective is to develop a solution to improve the knowledge of land availability and the information needed to develop land on a territory.

For the prospector, finding a plot of land adapted to the expectations and search criteria requires a good knowledge of several elements on the ground: in particular, the exact geographical limits, future urban planning assignments, the parts reserved for public facilities and development roads, the constructible and non-constructible parts, etc. [10]. All these constraints and others related to administrative procedures make land prospecting even more difficult.

Also, good land prospecting usually requires multiple intermediaries, due to the diversity of data necessary for a successful prospecting. As professionals in the field, we have encountered this problem for many years. To acquire the necessary multiple kinds of information, the prospector must approach a topographical surveyor regarding registration status and land, an urban planning organization, the municipality regarding the economy of the prospecting area, etc. These different elements oblige prospectors to invest more in human and technical resources in order to master the land prospecting process.

In this study, we are interested in improving the traditional processes of land prospecting and combating the need of multiple intermediaries. Indeed, we propose a "Geo-Prospecting” approach

${ }^{1}$ Wiegelmann T (2012) Risikoeinschätzung in der Immobilien-Projektentwicklung, in: Immobilien \& Finanzierung, 08 - 2012, pp. $261-263$. 


\section{Annals of Social Sciences \& Management studies}

based on the coupling of ICT and GIS as well as GPS in order to improve and simplify land prospecting for users (professionals and/or non-professionals) and to increase the availability of real-time information needed to know the real estate market by optimizing the time of preliminary feasibility studies. To this end, we believe it is necessary to implement a spatial reference platform named "Geo-P-Land" to provide a good, practical, and simple solution to all users interested in a territory.

The development of the Geo-Prospecting approach led us to ask some initial questions, namely:

How can this approach simplify user access to land and urban planning data? How can it develop land prospecting?

Can Geo-prospecting reduce the time and cost of land prospecting? What are its limits and prospects?

From an editorial point of view, we first set out the context and problematic, followed by the materials and analysis methodology used in this article. Then, we presented the application process in detail, which was limited, for instance, to the territory of the city of Casablanca, Morocco, as a test area. We later presented the obtained results which were confirmed and validated through interviews with a number of professionals in the field. Finally, we closed our study with conclusions and perspectives that will be discussed in another work.

\section{Material and Methods}

\section{Material}

In this article, we limit ourselves to engaging two types of data among the multitudes of data that must be mastered for better land prospecting. Indeed, we only use here data related to land and urban planning: data that we find essential in the field of real estate, because they have a significant influence on the value of the land prospected.

The parcel plan: is the set of boundaries of the land parcels registered and listed in the land registry database. These boundaries are well defined by geographical (degrees, minutes, and seconds) or Cartesian coordinates ( $x, y)$, with associated attribute information (area, title number, owner, land charge, etc.).

Urban plans: allow to control urban development on a territory, by drawing the strategic perspectives and detailed plans to be respected by the builder, developers, etc.

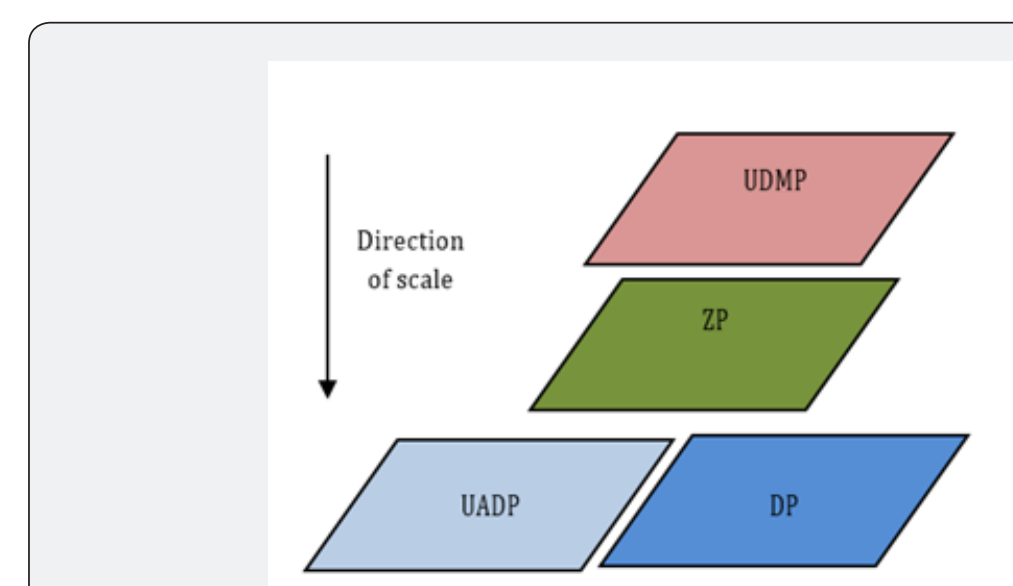

Study area
The UDMP is carried out on a large scale because it is a strategic document that provides advice and guidance for urban planning.

The ZP is established on a medium scale because its purpose is to define the limits of the zones of a territory.

The DP and the UADP are carried out on a small scale. They provide detailed information and provisions to be respected by the developer and the builder.

Figure 1: The order of scale of the intervention of urban planning documents in Morocco.

In addition, urban planning documents (town planning documents) exist in the form of reports and plans, with different scales depending on their use. These documents exist in all countries, even if they have different names, but they have the same operating principle. In Morocco (Law 12-90²), several types of urban planning documents can be cited in Figure 1, namely:

i. The urban development master plan (UDMP).

ii. The zoning plan (ZP). iii. The rural agglomeration development plan (UADP).

iv. The development plan (DP).

In this research, we relied on two types of data: the first relating to the land (the parcel plan) and the second relating to urban planning (the development plan) with their descriptive information (Figure 2).

In fact, we limited ourselves to using only these two types of data, because on the one hand, the DP in our experimental zone

${ }^{2}$ Source: http://www.muat.gov.ma/sites/default/files/Reglementation/Decret-n-2-92-832.pdf (verified on November 20, 2020). 
is a detailed and most precise plan compared to the UDMP or the ZP. On the other hand, the realization of small-scale documents $(1 / 2000$ and/or $1 / 5000)$ such as the DP and the UADP is mainly based on the perspectives and strategic lines of the UDMP (Law $\left.12-90^{3}\right)$. The use of the DP is therefore sufficient in terms of urban planning for this type of study.

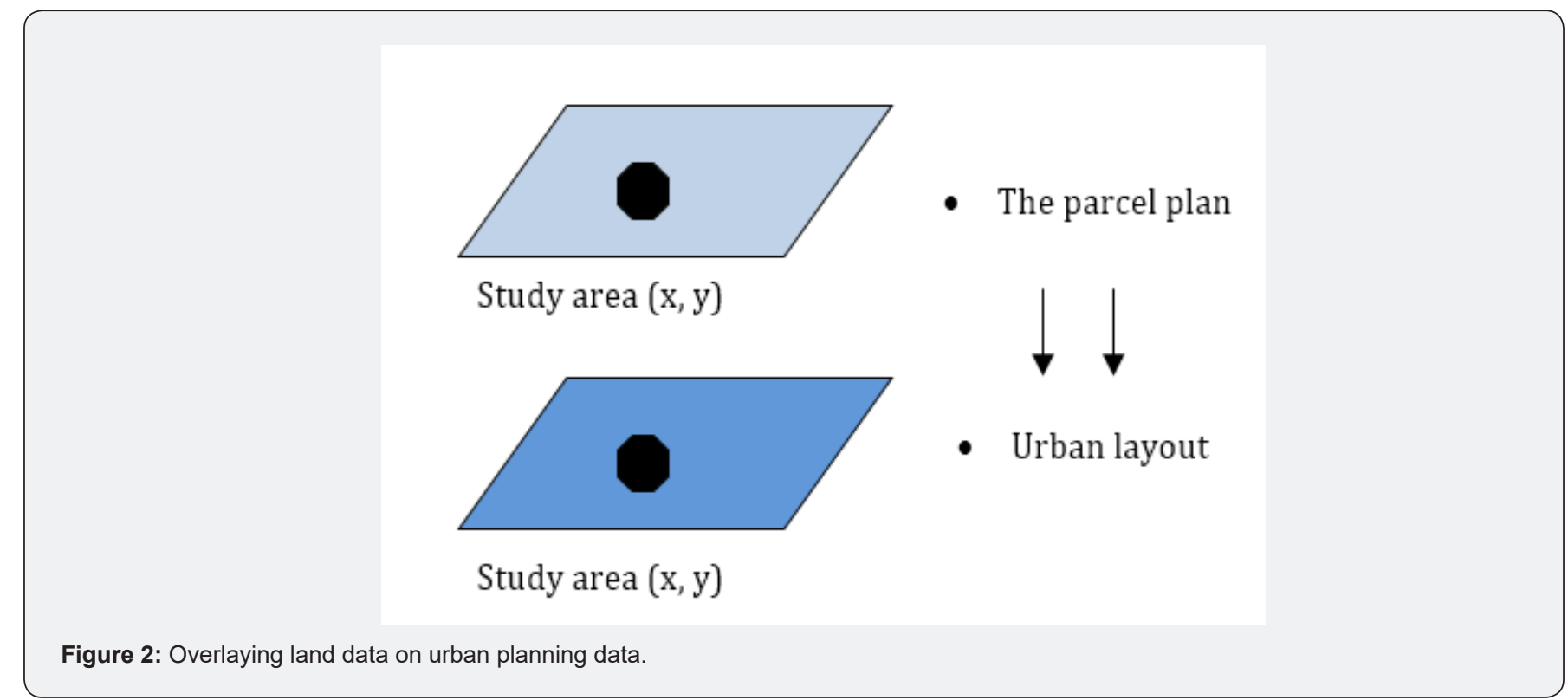

On the basis of the Geo-Prospecting approach, we want to develop and improve the land prospecting processes on a territory, using the graphic presentation of the DP and its provisions in terms of urban planning. As well as on the boundaries of the land shown on the parcel plan.

In the following paragraphs, we give the most details on the operating principles of the approach.

\section{Systemic analysis of and in the territory}

The approach used was a systemic analysis of the communication allowing to take measures in a territory. We were inspired by several methodological developments concerning multi-actor processes of land use planning. Our work was focused in simplifying and hastening the implementation of preliminary analyses related to land prospecting on a territory.

\section{Methodological approach}

Because our proposal should be applied in a territory, it is necessary to provide an overview of methodological developments concerning territories. To this end, we rely on several works of systemic analysis of territories [11-13]. According to the study carried by Moine, the territory is represented as a schematized system with different interacting elements. In fact, it is made of subsystems of geographical space, representation, and actors [12]. All these elements form a complex system.
The schematization of a designated territory as a system is presented as a tool for establishing a systemic analysis of the actions carried out there concerning technical processes, in particular those related to urban planning, land tenure, etc., in order to better organize and link the information resulting from the actions.

Moreover, any technical action carried out on a territorial system requires the intervention of multiple actors in several locations of the spatial subsystem. To fulfill a land survey, several particular actions are necessary to obtain a good result which are not always easy to master and might take time to be established. Thus, faced with this complex situation, we propose Geoprospecting to simplify and minimize the multiple intermediaries that can bring high costs to the prospectors (see paragraphs 2). Furthermore, this approach makes the territory information, which is the object of prospecting, available for consulting in real time. This means that our approach contributes to the establishment of democratic governance, by making information on a territory available to the general public (professional and non-professional), demonstrating transparency and reliability in order to foster a favorable climate to real estate and economic development in the broadest sense.

The following discussion provides more detail on the process of developing geo-prospecting and the preliminary analysis provided by this approach provides to prospectors. 


\section{Annals of Social Sciences \& Management studies}

\section{Elaboration of the Geo-prospecting}

The main factors in land prospecting are related to the geographical location of the land, the legal situation of the land, the urban planning situation of the land, the physical and/or structural possibilities of the land, the economic value of the land which is determined by other external factors such as the condition and possible uses of adjacent properties as well as the infrastructure and equipment provided by the public sector [14].

Taking these factors into account, we have schematized and constructed the Geo-Prospecting approach (Figures 3 \& 4) in two main steps:

i. The objective of the schematization phase is to gather all the elements necessary to develop a model, allowing the user to access a spatially referenced digital platform. This step consists in schematizing our model for the online publication of spatialized data.

ii. The conception phase allows the development of the Geo-P-Land platform dedicated to land prospecting for users.

GPS has been understood and accepted by the GIS community for many years (Table 1). They bring GIS directly into the field [15]. Advances in GPS and GIS technology have made it easier than ever to collect and disseminate data and manage spatial features. Here, in our methodology, through a coupling, ICTs further enhance the power and value effectiveness of GIS and GPS by providing communication during the land survey process via the Internet and the navigation tool used (Figure 4).

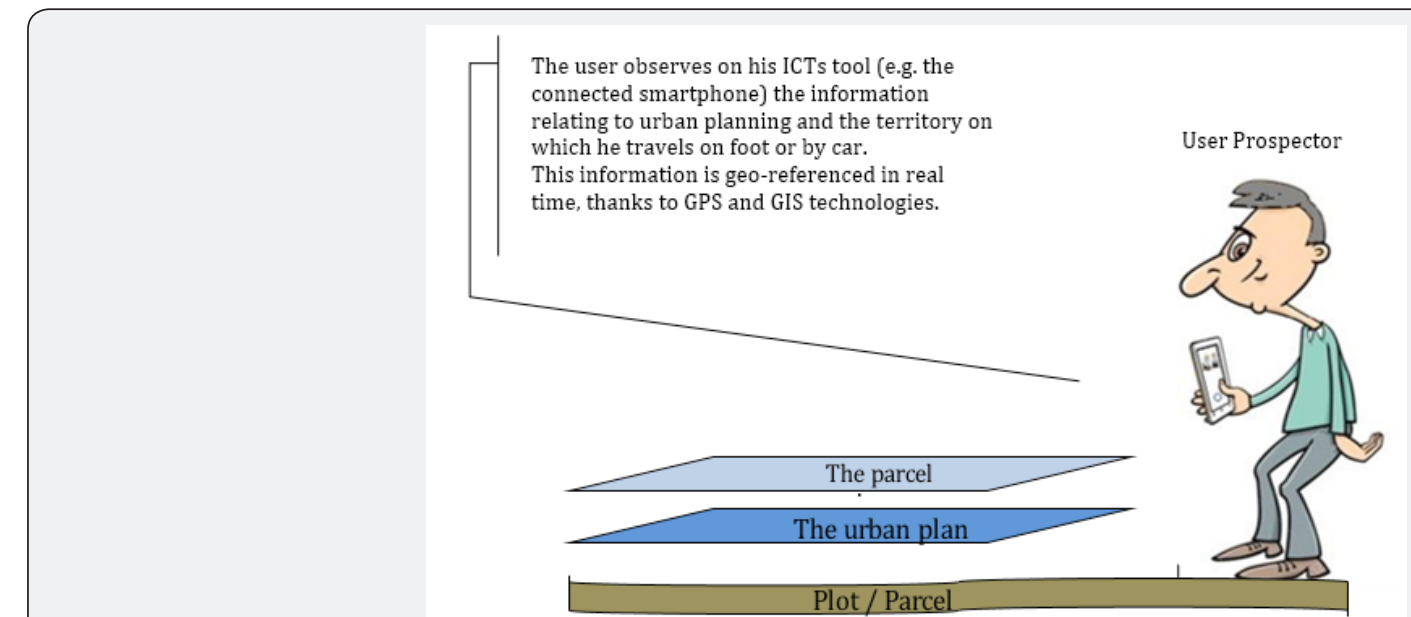

Figure 3: Overlay of urban planning data on land data via the Geo-P-Land with spatial reference on smartphone.

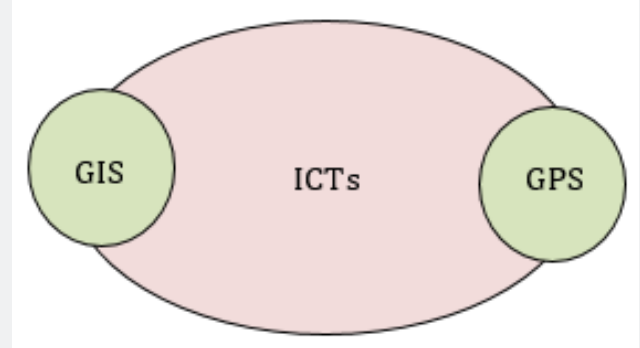

Figure 4: Coupling of technological tools in the Geo-Prospecting approach.

Table 1: Phasing of the Geo-Prospecting Geo-P-Land.

\begin{tabular}{|c|c|}
\hline Phasing & Description \\
\hline Schematization & Schematize the model by bringing together and integrating the basic tools: ICTs, GIS, and GPS. \\
\hline Conception & $\begin{array}{c}\text { Develop the online spatial reference Geo-P-Land platform on the basis of the previously established schema- } \\
\text { tization. }\end{array}$ \\
\hline
\end{tabular}

The combination of ICTs, GIS, and GPS allows the prospector to perform spatially and attribute analyses in real-time (Figure 5) from the thematic overlay on the Geo-P-Land of Geo-Prospecting. Thanks to GPS technology integrated on a smartphone or tablet connected to the Internet, the prospector user is spatially geolocated in real-time on the tracks of the urban plan and the parcel plan of the territory crossed on foot or by car. 


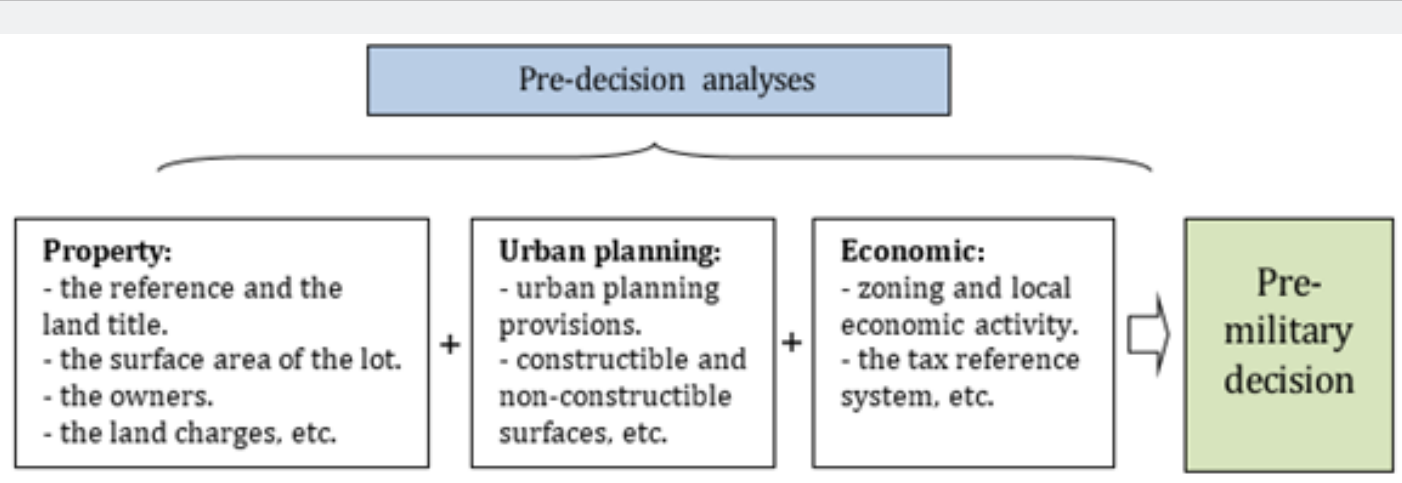

Figure 5: Analyses proposed by Geo-Prospecting on Geo-P-Land.

In Figure 5, we outline the main (preliminary) analyses for prospecting in the territory. In an attempt to meet the needs of prospectors, this diagram discusses three types of preliminary analyses in the field have prospected:

i. Land analysis: proposes a geographical, economic, and social inventory. It consists of providing the prospector with several basic information on a piece of land: status of the land (private or public), land charges (e.g. expropriation), surface area, etc.

ii. In Morocco, this analysis is very important because the country's land tenure system is characterized by a complexity linked to the diversity of legal status and the multiplicity of actors involved in land management [16].

iii. Urban planning analysis: In terms of land prospecting, knowledge of the different urban planning documents and their regulations is essential to find land. This analysis enables the identification of the constructible and non-constructible parts of the land, as well as all the elements related to the urban planning provisions.

iv. Economic analysis: this analysis is based mainly on information relating to the economic and socio-professional activities of the population in the land prospecting area.

These three analyses will be established on the Geo-P-Land of the Geo-Prospecting to facilitate decision making regarding a property (object of prospecting) crossed on foot or by car. Indeed, the superimposition of the multi-data established (in the form of layers), simplifies the urban planning and land analysis, optimizing the time/cost ratio during the consultation process in the departments concerned to have information on any terrain.

Furthermore, the Geo-P-Land can minimize the number of interventions by other actors in the land prospecting process. It allows the prospector to easily carry out a preliminary (indicative) in situ studies without any financial burden.

\section{Application and Results}

In this section, we demonstrate the application of the approach in the study area. First, we present the experimental area followed by the development processes of the "Geo-P-Land" platform (see the figure below indicating the articulation between the approach and the digital platform developed) (Figure 6).

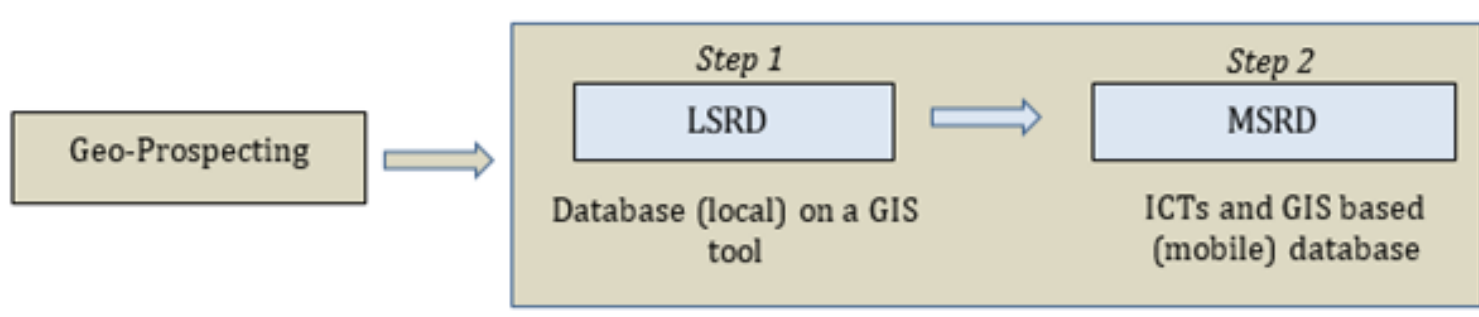

Proposed approach

Steps of the Geo-P-Land Digital Platform

Figure 6: Overview of the links between Geo-Prospecting and Geo-P-Land.

${ }^{4}$ Source: http://aub.ma/notre-r\%C3\%A9gion/la-r\%C3\%A9gion-de-casablanca-settat (verified on November 20, 2020). 


\section{Implementation of a digital platform}

According to our personal experience in the field of real estate as well as to our observations, the complexity of land prospecting is due to several elements: in particular, the availability and insufficiency of computerized information relating to urban planning and land tenure. Most of the information available for consultation is still in paper or electronic format but is not easily exploitable in the field.

In order to make more or less information available, in the traditional way, it is in the interest of the developer or planner to collaborate with a variety of actors, in particular: notaries, surveyors, construction companies, intermediaries on the ground, etc. This collaboration requires time and costs.

To test the proposed approach, we chose the CasablancaSettat region in Morocco, (Figure 7). This territory covers an area of 19,448 km2 and has 6,862,000 inhabitants (RGPH1 2014 ${ }^{4}$ ). It is an important region for the country because it contributes to $32.4 \%$ of the national GDP ${ }^{5}$, while benefiting from the important port, airport, rail and road infrastructures that enhance the real estate sector by facilitating the movement of people and goods.

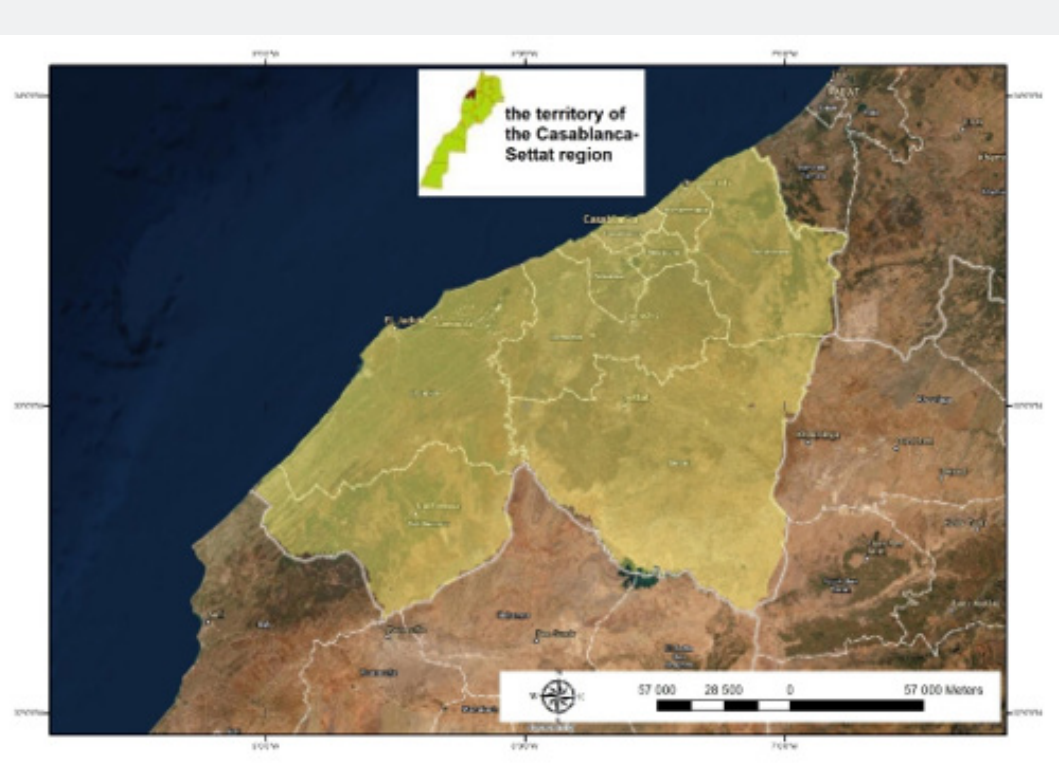

Figure 7: Location of the Study Area.

In addition to its importance in the country, the choice of the territory was also motivated by our experience and practical knowledge of urban planning and real estate in the region, as well as by the need declared by land professionals.

The development of the digital platform "Geo-P-Land" followed two main steps: first, to develop a local database that serves to gather the different data on a GIS tool; second, to create another mobile database that makes the information collected during the first step available to the prospector online. These two steps are detailed in the next two subsections.

\section{Local Spatial Reference Database (LSRD)}

As previously mentioned, we limit ourselves to integrating only urban planning and land data ${ }^{6}$ into our Geo-P-Land. The best land prospecting requires various elements from a multitude of domains, we can cite a few examples:

i. Urban plan (present and future). ii. Land use map (activities and natural resources).

iii. Drawing of hydrographic networks and water tables.

iv. Drawing of transportation networks.

v. Pollution information (air, noise, water, magnetic, etc.).

vi. Metrological information.

vii. Precipitation information.

viii. Maps on the morpho-pedological suitability of the soil.

ix. Topographical information.

x. Administrative boundaries.

xi. Information related to economic, industrial, etc. activities.

xii. Information related to taxes (price estimation reference frame) and estimated costs of administrative procedures.

${ }^{5}$ Source: http://casablanca.ma/RS/Doc/monographie-region-2015.pdf (verified on November 20, 2020).

${ }^{6}$ In Morocco, urban planning data come from urban agencies, and land data from the national agency for land conservation, registry and cartography. 
xiii. Information related to the prices of raw materials and labor in the territory.

xiv. General information related to the territory in question in terms of interesting construction projects, existing offers, needs, etc.
All this information must be integrated into a single LSRD to make it spatialized, then transmitted to a Mobile Spatial Reference Database (MSRD) to make it navigable and searchable online and in realtime by prospecting users (Figure 8).

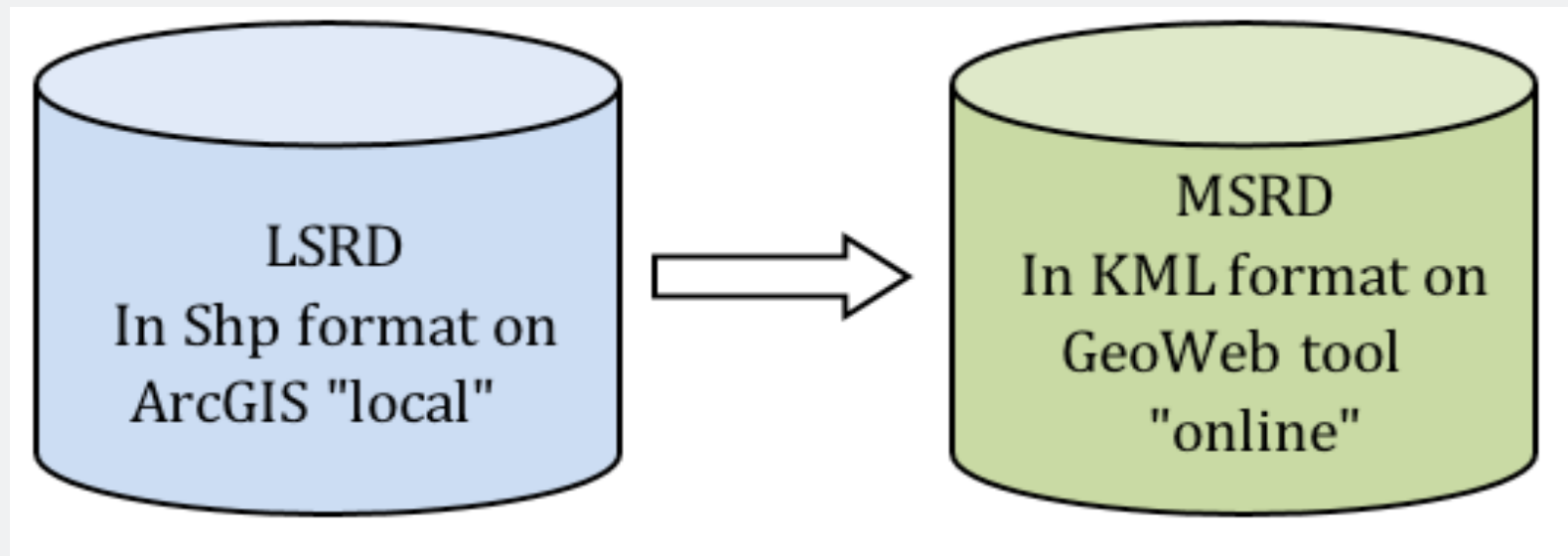

Figure 8: Transformation of LSRD to MSRD.

In this document, we limit ourselves to capitalizing and spatializing only the DP and the parcel plan. These two types of data are collected in an LSRD on the ArcGIS software in Shp format and then converted into KML to integrate them into the MSRD.

\section{Intermediate conversion (from Shp to KML)}

In order to make the information in the local database (LSRD) available online in real time on the MSRD, we need to transform the data set into KML format. The steps to follow to convert the Shp format to KML format are as follows:

i. After creating the LSRD on $\operatorname{ArcGIS}^{7}$ and acquiring and entering all the necessary data related to the DP and the Casablanca parcel plan, the first step is to use the ArcGIS ArcToolbox module, then click on the "convert Shp to KML" tool and define the link to save the file. Then, in the same interface on ArcToolbox, we use the "projection and transformation" tool, by defining the output projection "GCS_WGS_1984" and Marchich Lambert Maroc zone $1^{8}$.

\section{Mobile Spatial Reference Database (MSRD)}

After converting all the data (urban and land) into KML, it is necessary to proceed with their integration into the MSRD (Geo-P-Land). We have adapted the latter for the territory of the Casablanca-Settat region by introducing the data related to this territory.
Indeed, Using ICTs tools such as the internet, smartphones, tablets, or any other tool adapted to GPS technologies, and on a GeoWeb tool (e.g. Google Mymaps ${ }^{9}$ ), we insert the plots of the DP and the land parcel of the territory.

On a GeoWeb tool, we followed two steps to set up our Geo-PLand platform:

i. Create an online account on My maps google.

ii. Insert the data in KML format: we have to download the files in KML format, previously created on the GIS tool (ArcGIS).

Having developed the Geo-P-Land platform based on the geoprospecting approach, and respecting the steps described above, the platform can now be used in the study area. We will detail the results obtained in the section below.

\section{Application Results}

By moving on foot or by vehicle, on the territory of the Casablanca-Settat region, our Geo-P-Land allows prospectors using ICTs (internet, smartphones adapted to GPS technology, etc.) to exploit several data and to know perfectly in situ and in real time the necessary information (geographical and descriptive): the delimitation of building zones, development paths, green spaces, equipment, etc., and this by relying on the spatial geo localization of the DP and the land parcel plan with their descriptive information.

${ }^{7} \mathrm{~A}$ GIS software established by the American company ESRI.

${ }^{8}$ The cartographic projection system used in Morocco.

${ }^{9} \mathrm{~A}$ GeoWeb tool offered by Google. It remains a simple test tool in this study. A mobile application is envisaged for the city of Casablanca, with the integration of several other data available and useful for the best land prospecting. 
The Geo-P-Land allows professionals to efficiently prospect for land. They can consult the DP's zoning boundaries and the land title boundaries that cover it in the field (Figure 9). This simplifies user access to the data.

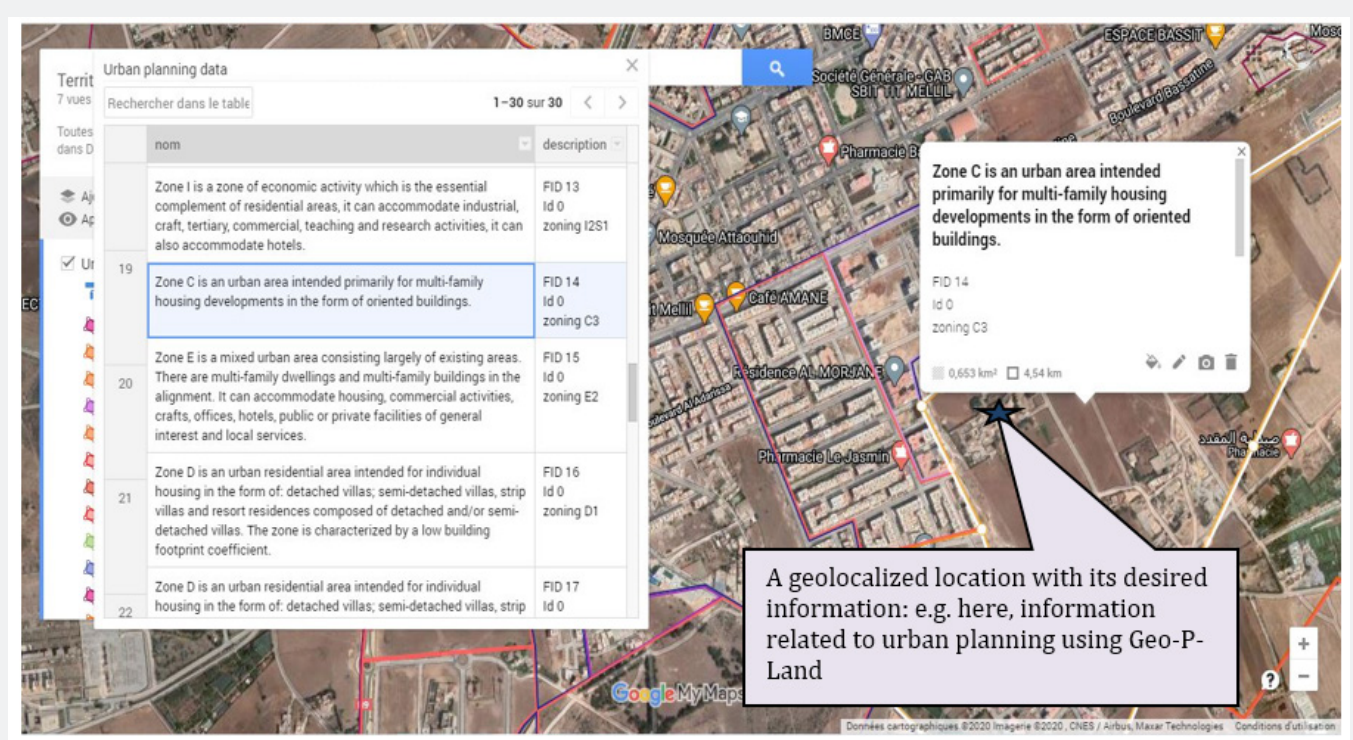

Figure 9: Geo-P-Land interface: online, navigable, and spatially referenced platform.

Traditional methods are not sufficient as they require several interventions in the office and in the field (e.g. the surveyor topographer), also using traditional methods such as digitizing extracts from information notes ${ }^{10}$ and computer-aided drafting (CAD) tools to export the coordinates ( $\mathrm{x}$ and $\mathrm{y}$ ) and implement them in the field (to determine the boundaries of constructible as well as non-developable areas).

In general, real estate is defined as a triangle of space, money and time [14]. Our Geo-P land's purpose is to optimize the time and cost of collecting the multi-data necessary for a good land prospecting, by detecting the available land and avoiding staying in a position of waiting for proposals. It offers the possibility to follow the evolution of urban planning documents and parcel plans to allow the land transfer on the territory of the CasablancaSettat region.

In order to verify the validity of geo-prospecting, we conducted interviews with 20 participants by asking them a few questions on the digital platform developed (see Appendix). The results we obtained are encouraging:

i. 18 participants feel they have enough knowledge to work on our proposal. They are also willing to use Geo-P-Land.

ii. $97 / 100$ is the score given to the proposal by the participants. This score is obtained by averaging all the values given (out of 100) by the twenty respondents.
This interview is only a means of confirming the results obtained. It does not correspond to a known methodology in terms of questioning. This interview was conducted with the randomly selected participants, as it follows:

- 5 building and construction professionals (1 civil engineer, 2 survey technicians and 2 architect-urbanists)

- 5 employees of real estate companies (we targeted 5 large companies with one employee from each)

- 5 non-specialists (residents of the Casablanca-Settat region)

- 5 land prospectors in the study area.

After having explored the proposal and having experimented it in the test area, we would like to bring forth some conclusions, elements for reflection and avenues for future work in the field.

\section{Conclusion and Perspectives}

As we have pointed out, traditional land prospecting requires multiple interventions and interims, which is costly for the prospectors. Here, the Geo-prospecting approach facilitates the technical processes of land prospecting and reduces investment costs to a minimum, while saving time: it provides an in-situ land, urban and economic analysis of the prospecting territory. In general, we can say that our proposal contributes to the development of existing solutions concerning real estate by

${ }^{10} \mathrm{~A}$ note necessary to have urban planning information on a plot of land. It is issued by the urban agencies, in two parts: a graphic extract of the DP and a report containing the zoning definitions. 


\section{Annals of Social Sciences \& Management studies}

simplifying the tasks of prospectors.

Thus, the originality of our work lies in the conjunction of multiple disciplines: information and communication sciences, by evoking systemic analysis; geomatics, by calling upon GIS and GPS; land tenure, by highlighting land prospecting; and urban planning, by relying on related documents and their analysis.

We believe this proposal contributed to advance the land survey methods through a simple and effective approach for prospectors. The application has given satisfactory results thanks to the incorporation of the suggested method that tries to promote autonomy in land prospecting and the democratization of information related to urban planning and land. It responds to the (assessed) needs of users/prospectors (promoters, developers of land, etc.) in the Casablanca-Settat region.

We have demonstrated the importance of combining ICTs, GIS and GPS in real estate development by simplifying the implementation of information from different sources to improve the analysis of urban space and land dynamics. In addition, by identifying the risks that may be present during the prospecting process.

As part of future enhancements, a mobile application dedicated to prospectors will be proposed, integrating all spatialized data from various domains (e.g., urban planning hydraulic, geotechnical and pollution data). The application will be tested on several other territories.

The proposed approach makes it possible to efficiently evaluate the land to be prospected, as well as to capitalize on the information required for real estate development and put it in the hands of the prospectors. It also contributes to the development of methodological tools and opens up new avenues of reflection in the field.

Finally, we have identified some perspectives in the form of questions that will be the subject of further research: can the integration of technical data in the Geo-Prospecting approach further simplify the feasibility study of a property by the (nonspecialized) prospector on a territory? How can the land that is subject to land prospecting be evaluated in a simple and efficient way by superimposing all the necessary data differences?

Annex: confirmation interview form.

Confirmation interview about the Geo-P-Land regarding land prospectors in the Casablanca-Settat region

1) Occupational Category:

- $\quad$ Building and construction engineer or technician

- $\quad$ Employee of a real estate company

- $\quad$ Land surveyor

- $\quad$ Non-specialist

2) If you are a professional, how many years of experience do you have?

3) Is it difficult to collect data on land survey in your area?

4) What suggestions do you have for improving the land survey process?

5) How often do you use ICT and GIS tools?

6) Following our demonstration of how Geo-P-Land works, do you think you have enough knowledge to use this tool?

7) Are you convinced? Indicate the degree of success and satisfaction on the scale with an (x):

\section{References}

1. Barkham R (1997) The financial structure and ethos of property companies: An empirical analysis. Construction Management \& Economics 15(5): 441-456.
2. Byrne PJ (1996) Risk, uncertainty and decision-making in property development. ( $2^{\text {nd }}$ edn.), E \& FN Spon.

3. Isenhöfer B (1999) Strategisches Management von Projektentwicklungsunternehmen, Müller (Vol. 8). 
4. Fisher P, Robson S (2006) The perception and management of risk in UK office property development. Journal of Property Research 23(2): 135-161.

5. Ratcliffe J, Stubbs M, Keeping M (2009) Urban planning and real estate development, ( $3^{\text {rd }}$ edn.), Routledge.

6. Wiegelmann T (2012) Risikoeinschätzung in der ImmobilienProjektentwicklung. Immobilien \& Finanzierung, pp. 261-263.

7. ISAAC, D O’leary J, Daley M (2010) Property Development: Appraisa and Finance, (2 ${ }^{\text {nd }}$ edn.), Palgrave Macmillan, United Kingdom.

8. Tiesdell S, Adams D (2011) Real estate development, urban design and the tools approach to public policy. Urban Design in the Real Estate Development Process 1-33.

9. Gehner E (2008) Knowingly taking risk - Investment decision making in real estate development, Eburon.

10. Hijab A (2019) An Intelligent Approach to Prospecting Real Estate and Real Estate Development. Communication presented to ICCCT 2019: International Conference on Cognitive Communications and Technologies, Zurich, Switzerland, p380.
11. Rolland-May C (2000) Evaluation des territoires: concepts, modèle, méthodes. Paris, Ed. Hermès, pp.95-97.

12. Moine A (2006) Le territoire comme un système complexe: un concept opératoire pour l'aménagement et la géographie. L'Espace géographique 35(2): 115-132.

13. Moine A (2008) Le territoire: comment observer un système complexe. L'Harmattan, p176.

14. Wiegelmann TW (2012) Risk Management in the Real Estate Development Industry. Robina: Institute of Sustainable Development \& Architecture.

15. Harrington A (2000) GIS and GPS: Technologies that work well together In Proceedings in the ESRI User Conference, San Diego, California.

16. World Bank (2008) Étude de marchés foncières pour la croissance économique: Héritage et structures foncières au Maroc: Les contraintes structurelles et institutionnelles à l'émergence d'un marché efficient du foncier au Maroc.

Your next submission with Juniper Publishers
will reach you the below assets
- Quality Editorial service
- Swift Peer Review
- Reprints availability
- E-prints Service
- Manuscript Podcast for convenient understanding
- Global attainment for your research
- Manuscript accessibility in different formats
( Pdf, E-pub, Full Text, Audio)
- Unceasing customer service
Track the below URL for one-step submission
https://juniperpublishers.com/online-submission.php

DOI: 10.19080/ASM.2021.06.555692 